\title{
Long-term outcomes after acute hypercapnic COPD exacerbation
}

\author{
First-ever episode of non-invasive ventilation
}

\author{
Andreas S. Fazekas - Mei Aboulghaith - Ruxandra C. Kriz · Matthias Urban · Marie-Kathrin Breyer · Robab Breyer- \\ Kohansal · Otto-Chris Burghuber · Sylvia Hartl · Georg-Christian Funk
}

Received: 27 January 2017 / Accepted: 4 July 2018 / Published online: 31 July 2018

(C) The Author(s) 2018

\begin{abstract}
Summary
Background Non-invasive ventilation (NIV) is used to treat acute hypercapnic respiratory failure (AHRF) in patients with chronic obstructive pulmonary disease (COPD); however, long-term outcomes following discharge are largely unknown. This study aimed to characterize long-term outcomes and identify associated markers in patients with COPD after surviving the first episode of HRF requiring NIV.

Methods This study retrospectively analyzed 122 patients, mean age $62 \pm 8$ years, $52 \%$ female and forced expiratory volume in $1 \mathrm{~s}$ (FEV1) predicted $30 \pm 13 \%$,
\end{abstract}

All anonymized data sets of our study are available through direct request to the corresponding author.

Authors' contributions GCF designed the study and conducted the data analysis. AF collected the data and drafted the manuscript. MA and RK collected the data. MU, RBK, MKB, SH and OCB critically revised the manuscript. All authors read and approved the final manuscript.

Electronic supplementary material The online version of this article (https://doi.org/10.1007/s00508-018-1364-6) contains supplementary material, which is available to authorized users.

A. S. Fazekas · M. Urban · M.-K. Breyer · R. Breyer-Kohansal • O.-C. Burghuber · S. Hartl · G.-C. Funk $(\bowtie)$

Department of Respiratory Medicine and Critical Care, Otto Wagner Hospital, Baumgartner Höhe 1, 1140 Vienna, Austria georg-christian.funk@meduniwien.ac.at

A. S. Fazekas · M. Aboulghaith · R. C. Kriz · M. Urban · M.-K. Breyer · R. Breyer-Kohansal · O.-C. Burghuber . S. Hartl · G.-C. Funk

Ludwig Boltzmann Institute for COPD and Respiratory

Epidemiology, Vienna, Austria

G.-C. Funk

Medical University of Vienna, Vienna, Austria admitted with an acute hypercapnic exacerbation of COPD and receiving a first-ever NIV treatment between 2000 and 2012.

Results A total of $40 \%$ of the patients required hospital readmission due to respiratory reasons within 1 year. Persistent hypercapnia leading to the prescription of domiciliary NIV, older age and lower body mass index (BMI) were risk factors for readmission due to respiratory reasons. Survival rates were $79 \%$ and $63 \%$ at 1 and 2 years after discharge, respectively. A shorter time to readmission and recurrent hypercapnic failure, lower BMI and acidemia on the first admission, as well as hypercapnia at hospital discharge were correlated with a decreased long-term survival.

Conclusion Patients with COPD surviving their first episode of AHRF requiring NIV are at high risk for readmission and death. Severe respiratory acidosis, chronic respiratory failure and a lower BMI imply shorter long-term survival.

Keywords COPD · COPD exacerbation · Non-invasive ventilation $\cdot$ Long-term outcome

\section{Take home message}

- Patients with COPD surviving their first episode of hypercapnic respiratory failure (AHRF) requiring noninvasive ventilation (NIV) are at high risk for readmission and death

- Severe respiratory acidosis, chronic respiratory failure and a lower BMI imply shorter long-term survival 


\section{Introduction}

Chronic obstructive pulmonary disease (COPD) is the third most common cause of death worldwide, resulting in an enormous burden on patients and on healthcare systems [1]. Mortality is increased in both the short-term and long-term period following an acute exacerbation of the disease [2]. Patients with COPD and acute respiratory failure face a high inhospital mortality of $17-49 \%$ [3-5, 8]. Exacerbations become more frequent and more severe as COPD progresses [6]. The course of COPD involves a rapid decline in health status after the second severe exacerbation and high mortality in the weeks following a severe exacerbation [7]. Long-term mortality rate during the 4 years following hospital admission for acute exacerbation of COPD is high (45\%) [9]. Severe exacerbations with acute hypercapnic respiratory failure (AHRF) may warrant admission to the intensive care unit (ICU) for non-invasive ventilation (NIV) [10]. Patients surviving such a respiratory crisis are at high risk for readmission and death $[5,11]$. Associated markers of outcome following hospitalization for exacerbations of COPD were reviewed extensively by Steer et al. in 2010 [12] and Singanayagam et al. in 2013 [2]. In patients requiring mechanical ventilation, the available literature focused almost exclusively on long-term outcome after COPD exacerbations treated with invasive ventilation in patient cohorts derived from the 1990s. Either no or inconsistent potentially predictive markers for long-term outcomes were identified in these studies [13-22]. Few studies focused on the outcome following primary NIV, the current therapeutic gold standard. In particular, the long-term outcome in COPD patients surviving a hypercapnic exacerbation treated with NIV on the intensive care unit (ICU) has not been given sufficient attention to date. Therefore, the aim of this study was to characterize the long-term outcome after hypercapnic COPD exacerbations requiring NIV in the ICU and to investigate associated markers.

\section{Methods}

\section{Setting}

The Department for Respiratory and Critical Care at the Otto Wagner Hospital is a pulmonary tertiary care center in Vienna, Austria, providing a broad range of pulmonary care including an intensive care unit (ICU). The ICU receives patients from emergency services, affiliated hospitals and from the wards within the Otto Wagner Hospital. The use of NIV for acute hypercapnic exacerbations of COPD is provided only in the ICU and not on regular wards at this hospital. Therefore, all patients acutely requiring NIV are admitted to the ICU. For those patients receiving a prescription of domiciliary NIV following discharge, training in the use of home NIV is provided on our respiratory monitoring unit (RMU).

\section{Patients}

The ICU records where searched for patients admitted with a diagnosis of COPD. Patients admitted to the ICU for NIV were included if the following criteria were met: age $>18$ years at index admission, underlying diagnosis of COPD as judged by the admitting physician, acute hypercapnic respiratory failure (AHRF; $\mathrm{pH}<7.35$, paCO2 $>45 \mathrm{~mm} \mathrm{Hg}$ ), primary treatment with non-invasive ventilation (with or without secondary endotracheal intubation) and survival to hospital discharge. All patients received standard medical care for COPD exacerbations based on the Global Initiative for Chronic Obstructive Lung Disease (GOLD) clinical guidelines.

Patients were excluded in the presence of the following: cardiopulmonary resuscitation or surgery immediately prior to the admission to the ICU, respiratory failure due to other causes (e.g. pulmonary embolism, acute myocardial infarction, asthma, bronchiectasis, bilateral pneumonia), prior resection of more than one lung lobe, obstructive sleep apnoea (OSAS), obesity hypoventilation syndrome (OHS), active cancer and congestive heart failure (CHF), i.e. history of hospitalization due to CHF, echocardiographic evidence of reduced left ventricular ejection fraction.

\section{Ethics}

The study was conducted according to the principles of the Declaration of Helsinki. The ethics committee of the city of Vienna granted an exemption from requiring ethics approval (reference number EK 09197_NZ). Given the retrospective, observational design of the trial, the need for informed consent was waived.

\section{Study design}

The main study objective was to identify prognostic markers for long-term outcome in COPD patients surviving their first episode of HRF requiring NIV. Prognostic markers for predefined endpoints including survival (time between discharge and death), readmission due to respiratory reasons and recurrence of AHRF necessitating readmission to the ICU with a further episode of ventilatory support were sought. The following data sets were collected from the index admission, at hospital discharge and during follow-up:

\section{Data from index admission}

- Age

- Sex (male/female) 
- Height $(\mathrm{cm})$, body weight $(\mathrm{kg})$, body mass index (BMI)

- History of previous intubation (y/n)

- Date of ICU admission

- COPD stage as based on lung function during a stable period within \pm 3 months of admission (FEV1/ FVC ratio $<70 \%$ and FEV1\%, whereby Forced Vital Capacity [FVC])

- Simplified Acute Physiology Score (SAPS) II+estimated mortality

- Secondary Intubation (y/n), date of intubation, days spent intubated

- Days spent on non-invasive ventilation (NIV)

- Arterial blood gas (ABG) on admission including $\mathrm{pH}, \mathrm{CO} 2, \mathrm{FiO} 2, \mathrm{paO} 2$ and $\mathrm{paO} 2 / \mathrm{FiO} 2$ ratio

- Respiratory rate at the institution of NIV

- Highest C-reactive protein (CRP) value within 3 days of admission (mg/dl)

- Use of hemodiafiltration (y/n)

- Maximum Therapeutic Intervention Scoring System (TISS28) score

- Presence of ICU-acquired pneumonia (y/n)

- Haemoglobin on admission (g/dl)

- Inspiratory Positive Airways Pressure (IPAP) and Positive End-Expiratory Pressure (PEEP) settings used at initiation of NIV

- Date of ICU discharge, length of ICU stay.

\section{Data on hospital discharge}

- Date of hospital discharge, length of hospital stay

- Arterial blood gas (ABG) at discharge

- Prescription of Long Term Oxygen Therapy (LTOT) \pm NIV on discharge

\section{Endpoints during follow-up}

- Hospital readmission due to respiratory causes (y/n, date), whereas the term "respiratory reasons" was used as a header for any readmission due to an underlying pathology in the respiratory system (e.g. pneumonia, bronchitis, exacerbation of COPD, pulmonary embolism), also including recurrent acute hypercapnic respiratory failure (AHRF)

- Death (y/n, date)

- Last date seen alive

\section{Definitions}

- Acute hypercapnic respiratory failure $(\mathrm{AHRF})=$ respiratory acidosis: $\mathrm{pH}<7.35$, paCO2 $>45 \mathrm{~mm} \mathrm{Hg}$

- Acidemia: $\mathrm{pH}<7.35$

- Hypoxemia: paO2/FiO2-ratio <300

- Hypercapnia=hypercapnic respiratory failure: paCO2 > $45 \mathrm{mmHg}$

- Persistent hypercapnia: paCO2 $>45 \mathrm{~mm} \mathrm{Hg}$ at discharge

The study was conducted as an investigator-initiated retrospective record review. The index admission was confined to a single center. Follow-up data were derived from a total of 11 centers within the Vienna Hos- pital Association (Wiener Krankenanstaltenverbund, $\mathrm{KAV}$ ), whereby there was no routine outpatient follow-up scheduled for the patients. All eligible patients treated within the study period were included. Survival time was defined by a patient's vital status. All patients not reported as deceased during the followup were considered to be alive.

\section{Data collection}

Data were extracted from electronic health records including the local ICU systems (medis, ICUdoc) as well as the city-wide health database (web.okra) of the Vienna Hospital Association. Data were anonymized and entered into an access database by three independent investigators. All the available data in the ICU health records going back to 2000 were used. Data collection was drawn to a close in 2012 when it was felt that enough patients were included to proceed to statistical analysis. It was chosen not to go back further than 2000 because of a shift in treatment paradigms (patients were more readily intubated in the 1990s). The city-wide health database was only used for follow-up.

\section{Analysis}

Data are presented as median and interquartile ranges or as mean and standard deviation $( \pm \mathrm{SD})$. After completion of data collection, data were cleaned and outliers ( $>95 \%$ confidence interval) were reconfirmed or corrected. Data were exported to a statistical software package (SPSS for Windows, version 15; SPSS Inc; Chicago, IL, USA) for analysis. Univariable data were described using standard methods. Association between risk factors and endpoints were assessed using bivariable and multivariable logistic regression (for dichotomous outcomes) or Cox regression (for timedependent outcomes). In order to address collinearity, the automatic variable selection algorithm of SPSS was used: all potential associated markers (see methods section) were entered in the model but only those variables kept by both the forward and the backward conditional selection algorithm were included in the final models. Kaplan-Meier curves were used to demonstrate survival and readmission characteristics. Statistical significance was defined as $p<0.05$.

\section{Results}

There were 939 ICU admissions with a recorded diagnosis of COPD during the study period between February 2000 and June 2012. A COPD was regularly found as a comorbidity and not as the main reason for admission, which lead to the exclusion of the majority of cases (817 out of 939 admissions). Reasons for exclusion and respective frequencies are shown in Table 1. Only the index admission of an individual 
Table 1 Reasons for excluded admissions

\begin{tabular}{|l|l|}
\hline Exclusion criteria & $\begin{array}{l}\text { Number of admissions (\% of } \\
\text { all excluded admission) }\end{array}$ \\
\hline Surgery within 48 h prior to ICU admission & $188(23)$ \\
\hline Respiratory failure due to other causes & $146(18)$ \\
\hline AHRF criteria not met & $88(11)$ \\
\hline Congestive heart failure & $81(10)$ \\
\hline Primary intubation & $78(10)$ \\
\hline OSAS & $66(8)$ \\
\hline Other/insufficient data & $52(6)$ \\
\hline Death before hospital discharge & $45(6)$ \\
\hline Active cancer & $45(6)$ \\
\hline CPR within 7 days prior to ICU admission & $28(3)$ \\
\hline $\begin{array}{l}\text { AHRF acute hypercapnic respiratory failure, OSAS obstructive sleep apnoea } \\
\text { syndrome, CPR cardiopulmonary resuscitation, ICU intensive care unit }\end{array}$ \\
\hline
\end{tabular}

patient was considered for inclusion and repeat admissions were attributed to follow-up data.

A total of 122 individual patients were included. Sex was evenly distributed, mean age was $62 \pm 8$ years and mean BMI was $25 \pm 6$. Spirometry was available in about half of the patients and indicated an emphasis on severe and very severe COPD stages with a mild degree of chronic hypercapnia. Of the patients $7(6 \%)$ had a record of previous intubation due to e.g. pneumonia or sepsis, whereas none of these 7 patients had a record of previous intubation due to an exacerbation of COPD at this institution. Of the patients $5(4.1 \%)$ were on domiciliary NIV prior to the admission. Demographics and spirometry results are outlined in Table 2.

Arterial blood gas analyses on admission showed acidemia, hypercapnia and hypoxemia (pH 7.25 \pm 0.07 ; $\mathrm{paCO}_{2} 77 \pm 17 \mathrm{mmHg}$; $\mathrm{paO}_{2} / \mathrm{FiO}_{2}$ ratio $256 \pm 115$; Ta-

Table 2 Demographics and spirometry results ble 3). Radiographic evidence of a unilateral pneumonic infiltrate was present in $10 \%$ of the patients. All patients were started on NIV using an assisted mode with moderate pressure settings (IPAP $19 \pm 4$ mbar, PEEP $6 \pm 2$ mbar). A respiratory rate of $22( \pm 8)$ per minute was recorded at the initiation of NIV and following initial pharmacological management. The NIV failed in 18 patients (15\%), necessitating secondary endotracheal intubation. No patient developed ventilator-associated or hospital-acquired pneumonia, sepsis or multi-organ failure.

The median hospital and ICU length of stay was 19 days (range 14-27 days) and 7 days (3-11 days), respectively. Arterial blood gas readings at hospital discharge were $\mathrm{pH} 7.4( \pm 0.05), \mathrm{paO}_{2} 81( \pm 23) \mathrm{mmHg}$ and $\mathrm{paCO}_{2} 53( \pm 11) \mathrm{mm} \mathrm{Hg}$. Of the patients $85(70 \%)$ received long-term oxygen treatment on hospital discharge and 26 patients $(21 \%)$ were prescribed domiciliary NIV. Follow-up duration was defined as time from the index admission to the last documented patient contact (i.e. hospital readmission, out-patient follow up or death). Median follow-up duration was 1117 days (663-1570 days). Overall readmission rates due to any respiratory reason including recurrent hypercapnic respiratory failure were $40 \%(29-51 \%)$ at 1 year, $46 \%(35-59 \%)$ at 2 years and $73 \%(58-87 \%)$ at 5 years. Median time to readmission due to respiratory reasons was 112 days (33-328 days; Fig. 1). Survival rates were $79 \%(72-86 \%)$ at 1 year, $63 \%(53-73 \%)$ at 2 years and $32 \%(21-43 \%)$ at 5 years (Fig. 2). Median time of survival was 536 days (24-1337 days). The citywide health database of Vienna includes all deaths, therefore there is no loss to follow-up with respect to death. Of the patients three $(2.5 \%)$ were lost to followup with respect to the endpoint readmission and/or HRF.

\begin{tabular}{l|l}
\hline Patients & $n=122$ \\
\hline Sex & Female: $n=63(52 \%)$ \\
\hline Age & $62( \pm 8)$ years \\
\hline Height & $166( \pm 9) \mathrm{cm}$ \\
\hline Weight & $69( \pm 19) \mathrm{kg}$ \\
\hline Body mass index & $25( \pm 6)$ \\
\hline History of previous intubation & $n=7(6 \%)$ \\
\hline Prior use of home NIV & $n=5(4 \%)$ \\
\hline COPD stage & $\begin{array}{l}\text { I: } n=0 \\
\text { II: } n=5(7 \%)\end{array}$ \\
\hline III: $n=19(26 \%)$ \\
IV: $n=48(67 \%)$
\end{tabular}

FEV1 forced expiratory volume in $1 \mathrm{~s}, A B G$ arterial blood gas, COPD chronic obstructive pulmonary disease, NIV non-invasive ventilation

${ }^{a}$ spirometry within 3 months of index admission was available in $46.7 \%$ of the patients 
Table 3 Data from the ICU admission

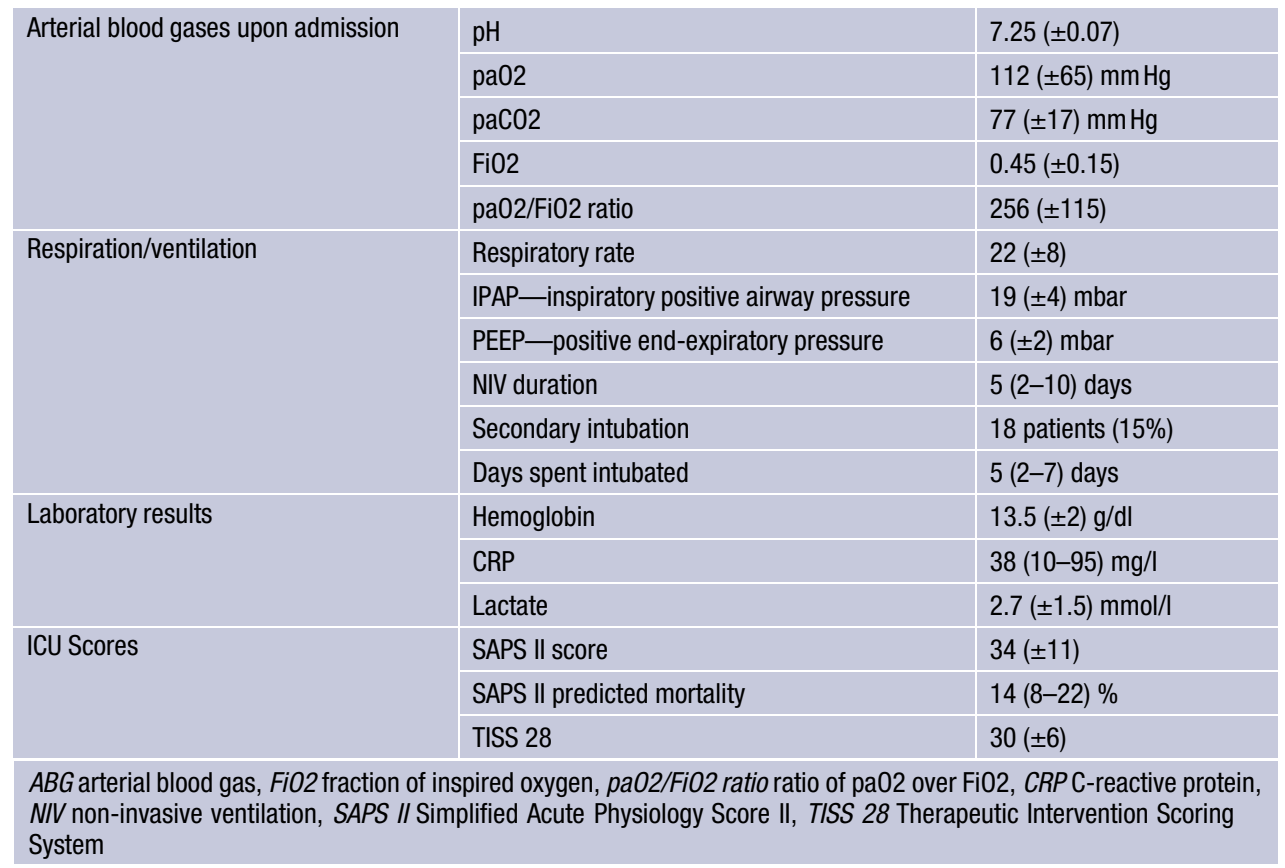

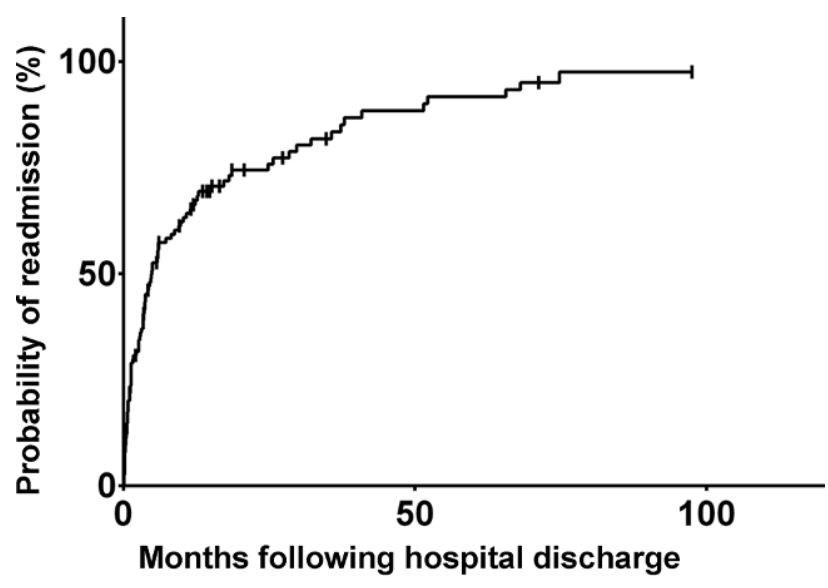

Fig. 1 Probability of readmission due to respiratory reasons following discharge at index admission

\section{Associated markers of readmission and death}

Associated markers of readmission to due respiratory reasons with or without hypercapnic respiratory failure

Multivariable Cox regression showed the following risk factors to be independently associated with a lower survival: lower $\mathrm{BMI}$, higher age and lower $\mathrm{paO} 2 / \mathrm{FiO} 2$ ratio on admission and a higher paCO2 on hospital discharge (Table 4).

\section{Associated markers of overall survival}

Multivariable Cox regression showed the following risk factors to be independently associated with a lower survival: lower BMI, lower $\mathrm{pH}$ and lower paO2/FiO2ratio on admission and a higher paCO2 on hospital discharge (Table 5).

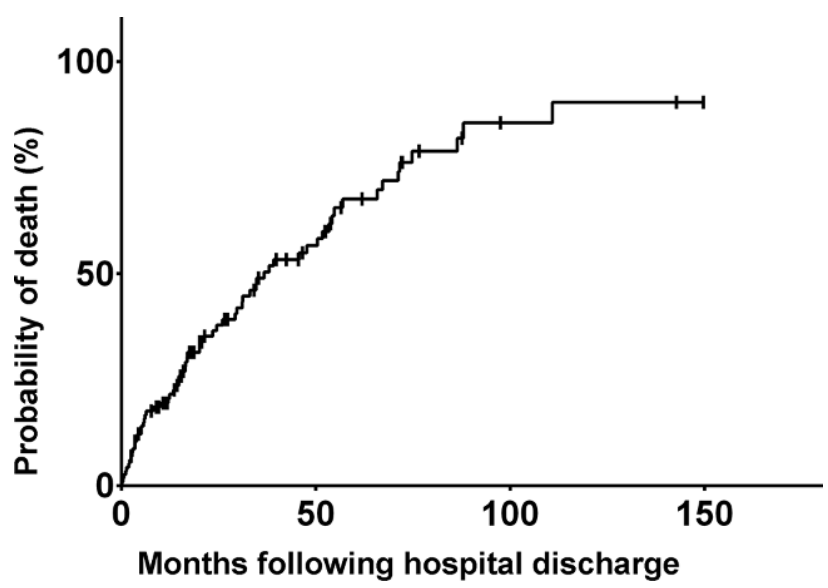

Fig. 2 Probability of death following discharge at index admission

\section{Discussion}

This article presents the first European study with an exclusive focus on long-term outcomes and associated markers in COPD patients surviving an episode of HRF requiring NIV in the ICU. This patient cohort faces a substantial long-term mortality with high rates of hospital readmission and recurrent hypercapnic respiratory failure. Of the patients $40 \%$ were readmitted due to respiratory reasons within 1 year. Survival rates were $79 \%$ and $63 \%$ at 1 and 2 years after discharge, respectively. Cox regression showed the use of domiciliary NIV, age, cachexia and hypoxemia on admission to be correlated with a higher likelihood of readmission due to respiratory reasons. A shorter time to readmission and recurrent hypercapnic failure, cachexia, acidemia, hypoxemia on admission, as 
Table 4 Associated markers of readmission to due respiratory reasons with or without hypercapnic respiratory failure in multivariable Cox regression

Table 5 Associated markers of overall survival in multivariable Cox regression

\begin{tabular}{|l|l|l|}
\hline & Hazard ratio & $p$ value \\
\hline Lower BMI & $0.96(0.92-0.99)$ & 0.019 \\
\hline Higher age, years & $1.02(1.00-1.05)$ & 0.060 \\
\hline Lower pa02/Fi02-ratio & $0.997(0.996-0.999)$ & 0.009 \\
\hline Persistent hypercapnia leading to prescription of home NIV & $1.97(1.21-3.22)$ & 0.006 \\
\hline BMI body mass index, NIV non-invasive ventilation & & \\
\hline
\end{tabular}

\begin{tabular}{|l|l|l|}
\hline & Hazard ratio & $p$ value \\
\hline Lower BMI & $0.94(0.91-0.98)$ & 0.0055 \\
\hline Lower pH & $0.003(0.000-0.187)$ & 0.0054 \\
\hline Lower pa02/Fi02 ratio & $0.997(0.995-1.000)$ & 0.0183 \\
\hline Higher paC02 on discharge & $1.030(1.005-1.056)$ & 0.0204 \\
\hline BMI body mass index & & \\
\hline
\end{tabular}

well as hypercapnia at discharge were correlated with an increased long-term mortality.

A range of markers as outlined above were found to be associated with long-term outcomes. It is remarkable to find an association between markers of acute physiology and long-term outcomes as shown in the association of the level of acidosis and hypoxemia on admission and lower long-term survival. It is speculated that a more severe derangement of acute physiology points towards exhausted compensatory mechanisms, which might indirectly influence longterm outcome. A range of candidate markers did not show a correlation with long-term markers in this cohort. Most notably the need for secondary intubation, COPD stage, SAPS3 II and TISS 28 scores, days spent on ventilation and length of hospital stay did not show a correlation with long-term outcomes. In this respect it should be emphasized that the sample exclusively comprised survivors of the acute hospitalization episode whereas patients not surviving to hospital discharge were excluded.

Few studies are available in the literature for direct comparison to this study. In a large Canadian study on long-term outcome following the first hospitalization for a COPD exacerbation, mortality rates were $50 \%$ at 3.6 years and $75 \%$ at 7.7 years [7]. Unsurprisingly, mortality following COPD exacerbation requiring NIV, as reported in this study, is even higher. There is a bulk of studies on in-hospital and long-term outcomes following invasive ventilation in COPD patients, derived from study periods mostly stemming from the 1990s; however there has been a major shift in care towards primary NIV [10] and the prevalence and prognosis of COPD in critically ill patients has changed substantially [23]. The use of NIV has increased significantly over time among patients hospitalized for acute exacerbations of COPD, whereas the need for intubation and in-hospital mortality has declined [24].

A total of three papers were identified with a research question comparable to this study [11, 25, 26]. The sample size ranged between 93 and 110 patients in these studies. Chu et al. [11] published data from an Asian cohort receiving NIV in a respiratory care unit (RCU) and 1 year after discharge $79.9 \%$ had been readmitted, $63.3 \%$ had another life-threatening event and $49.1 \%$ had died. There are notable differences in the patient characteristics in comparison to the present study. For example, the $\mathrm{Chu}$ et al. cohort consisted predominantly of men (87 male and 23 female patients), while sex was evenly balanced in our patients. The subjects in the Chu et al. study were on average a decade older (mean age 73.2 vs. 62 years), more likely to be cachectic (mean BMI 20 vs. 25 in this study) and half of the patients had evidence of a pneumonic infiltrate compared to $10 \%$ in this study. Furthermore, Chu et al. included patients with prior episodes of intra-hospital NIV use whereas this study focused solely on first time application of NIV. There was no prescription of domiciliary NIV following discharge in the Chu et al. cohort while one in five of patients in this study was prescribed domiciliary NIV because of persistent hypercapnia. Given these differences in patient characteristics, only limited conclusions can be drawn from the direct comparison to the study of Chu et al. Echave-Sustaeta et al. [26] reported a study from Madrid including a cohort of 93 COPD patients (mean age 70.7 years, $83 \%$ male) surviving an episode of hypercapnia with ward-based NIV. Of the patients $66 \%$ required readmission within the following year and 1-year survival was 69\%. Chung et al. [25] studied 100 patients in an Australian cohort (mean age 70.6 years, $56 \%$ male) also receiving wardbased NIV where $56 \%$ needed readmission within 1 year and survival rates at 2 and 5 years were $52 \%$ and $26 \%$, respectively. Potentially predictive markers that were identified in these studies are listed in table 6 in the online supplementary material. There is little inter-study reproducibility of potentially predictive markers. The only markers that were reproduced in another study were arterial $\mathrm{pH}$ prior to initiation of NIV and age in association with long-term mortality. Long-term survival is consistently poor across the 4 studies, with only 1 in 4 patients surviving 5 years following discharge. Given the high morbidity and mor- 
tality in COPD patients surviving an episode of HRF, it seems mandatory to discuss the prognosis with the patients and to elicit their wishes concerning readmission to ICU and possible reinstitution of ventilatory support.

The present study is limited by its retrospective design and a relatively small sample size. Furthermore, data on smoking status could not be obtained, LTOT prior to admission, length of stay in hospital in the year prior to admission, the Medical Research Council (MRC) dyspnea score and the Katz Index of Independence in Activities of Daily Living score (some of these factors have been identified as associated markers in other studies, as outlined in the online supplementary material). Spirometry within 3 months of admission was available in only half of the patients. Readmissions outside Vienna or in a private hospital within Vienna might have been missed. In an attempt to define this patient cohort as precisely as possible, relatively rigid exclusion criteria were used. It is acknowledged that this might have introduced some bias due to patient selection. The COPD is regularly found with a range of comorbidities that might themselves lead to respiratory failure. It was decided to attribute the cause of respiratory failure not solely to COPD (and therefore to exclude the patient) when there was recorded evidence of an acute illness that by itself may be reason enough to cause respiratory failure. It is acknowledged that it is difficult to adequately draw the line here in the presence of several comorbidities. As stated, all patients requiring NIV are admitted to the ICU at this hospital. The results may not be transferable to hospitals where NIV is also provided on regular wards.

The data point towards a lower BMI and chronic hypercapnia as targets for clinical intervention. Weight gain improves survival in undernourished patients with COPD [27]; however, methods to achieve a reliable weight gain in COPD patients remain elusive. The addition of long-term NIV to standard treatment improves survival of patients with stable hypercapnic COPD when NIV is targeted to greatly reduce hypercapnia [28]. In seems likely that these findings from stable COPD patients would also be observed in patients following acute hypercapnic respiratory failure. Struik et al. randomized 201 COPD patients with prolonged hypercapnia after ventilatory support for acute respiratory failure to either nocturnal NIV or standard care. An improvement in daytime pCO2 and trend to a better quality of life was found but no effect on mortality or readmission rate was seen after 1 year [29]. In patients who used NIV following an admission for an acute exacerbation of COPD (AECOPD) with AHRF, Galli et al. on the other hand found lower readmission rates and an improved event-free survival after 180 days from an index admission compared to patients who did not use NIV post-discharge [30].

In conclusion, there is substantial morbidity and mortality in this patient population. Promising tar- gets for intervention identified in this study, in line with previously published studies, are a low BMI and chronic hypercapnia. The authors believe that these findings should be validated in a prospective cohort leading to predictive models that can be used to facilitate the shared decision-making process.

\section{Conclusion}

Patients with COPD surviving the first episode of HRF requiring NIV are at high risk for readmission and death. Distinct risk factors associated with long-term outcomes were identified; however, there is substantial inconsistency among studies published in this field. Results from this study point towards a low BMI and chronic hypercapnia as possible targets for therapeutic intervention.

Acknowledgements The authors kindly thank the nursing staff of the intensive care units for their outstanding patient care.

Funding Open access funding provided by Medical University of Vienna.

\section{Compliance with ethical guidelines}

Conflict of interest A.S. Fazekas, M. Aboulghaith, R.C. Kriz, M. Urban, M.-K. Breyer, R. Breyer-Kohansal, O.-C. Burghuber, and S. Hartl declare that they have no competing interests. G.-C. Funk reports personal fees from Glaxo-Smith Kline, Boehringer Ingelheim, Astra Zeneca and Menarini during the conduct of the study.

Ethical standards The study was conducted according to the principles of the Declaration of Helsinki. The ethics committee of the city of Vienna granted an exemption from requiring ethics approval (reference number EK 09-197_NZ). Given the retrospective, observational design of the trial, the need for informed consent was waived.

Open Access This article is distributed under the terms of the Creative Commons Attribution 4.0 International License (http://creativecommons.org/licenses/by/4.0/), which permits unrestricted use, distribution, and reproduction in any medium, provided you give appropriate credit to the original author(s) and the source, provide a link to the Creative Commons license, and indicate if changes were made.

\section{References}

1. Burney PG, Patel J, Newson R, Minelli C, and Naghavi M. Global and regional trends in COPD mortality, 1990-2010. European Respiratory Journal. Eur Respiratory Soc 2015;45(5):1239-47.

2. Singanayagam A, Schembri S, Chalmers JD. Predictors of mortality in hospitalized adults with acute exacerbation of chronic obstructive pulmonary disease. Ann Am Thorac Soc. 2013;10(2):81-9.

3. Roberts CM, et al. Acidosis, non-invasive ventilation and mortality in hospitalised COPD exacerbations. Thorax. 2010;2010:153114.

4. Nawaid A, et al. Acute hypercapnic respiratory failure (AHRF): looking at long-term mortality, prescription of 
long-term oxygen therapy and chronic non-invasive ventilation (NIV). Clin Med. 2012;12.2:188-90.

5. Hartl S, et al. Risk of death and readmission of hospitaladmitted COPD exacerbations: European COPD Audit. European Respiratory Journal 2016 47:113-121, https:// doi.org/10.1183/13993003.01391-2014

6. Hurst JR, et al. Susceptibility to exacerbation in chronic obstructive pulmonary disease. New Engl J Med. 2010;363.12:1128-38.

7. Suissa S, Dell'AnielloS, Ernst P. Long-term natural history of chronic obstructive pulmonary disease: severe exacerbations and mortality. Thorax. 2012;67(11):957-63.

8. Hoogendoorn M, et al. Case fatality of COPD exacerbations: a meta-analysis and statistical modelling approach. Eur Respir J. 2011;37.3:508-15.

9. Piquet J, et al. High-risk patients following hospitalisation for an acute exacerbation of COPD. Eur Respir J. 2013;42.4:946-55.

10. From the Global Strategy for the Diagnosis, Management and Prevention of COPD, Global Initiative for Chronic Obstructive Lung Disease (GOLD) 2016. Available from: http://www.goldcopd.org/. Date last accessed: July 24 2016.

11. Chu CM, Chan VL, LinAWN, Wong IWY, Leung WS, Lai CKW. Readmission rates and life threatening events in COPD survivors treated with non-invasive ventilation for acute hypercapnic respiratory failure. Thorax. 2004;59(12):1020-5.

12. Steer J, Gibson GJ, Bourke SC. Predicting outcomes following hospitalization for acute exacerbations of COPD. QJM. 2010;103(11):817-29.

13. Seneff MG, Wagner DP, Wagner RP, Zimmerman JE, and Knaus WA. Hospital and 1-year survival of patients admitted to intensive care units with acute exacerbation of chronic obstructive pulmonary disease. Jama 1995;274(23):1852-7.

14. Connors AF Jr, Dawson NV, Thomas C, Harrell FE Jr, Desbiens N, Fulkerson WJ, Kussin P, Bellamy P, Goldman L, Knaus WA. Outcomes following acute exacerbation of severe chronic obstructive lung disease. The SUPPORT investigators (Study to Understand Prognoses and Preferences for Outcomes and Risks of Treatments). Am J Respir Crit Care Med. 1996;154(4):959-67.

15. Breen D, et al. Acute respiratory failure secondary to chronic obstructive pulmonary disease treated in the intensive care unit: a long term followup study. Thorax. 2002;57.1:29-33.

16. Groenewegen KH, Schols AM, Wouters EF. Mortality and Mortality-Related Factors After Hospitalization for Acute Exacerbation of COPD. CHEST. Journal. 2003;124(2):459-67.

17. Raurich JM et al. In-hospital and 2-year survival of patients treated with mechanical ventilation for acute exacerbation of COPD. Archivos de Bronconeumología (English Edition) 2004;40(7):295-300.

18. Ai-Ping C, Lee KH, Lim TK. In-hospital and 5-year mortality of patients treated in the ICU for acute exacerbation of COPD: Aretrospective study. Chest. 2005;128:518-24.

19. Rivera-Fernaìndez R, Navarrete-Navarro P, FernaìndezMondejar E, Rodriguez-Elvira M, Guerrero-Loìpez F,
Vaìzquez-Mata G. and Project for the Epidemiological Analysis of Critical Care Patients (PAEEC) Group. Six-year mortality and quality of life in critically ill patients with chronic obstructive pulmonary disease. Crit Care Med. 2006;34(9):2317-24.

20. Christensen S, Rasmussen L, Horvath-Puho E, Lenler-Petersen $\mathrm{P}$, Rhode $\mathrm{M}$, Johnsen SP. Arterial blood gas derangement and level of comorbidity are not predictors of longterm mortality of COPD patients treated with mechanical ventilation. Eur J Anaesthesiol. 2008;25(07):550-6.

21. Berkius J, Nolin T, Mårdh C, Karlström G, Walther SM, Intensive Care Registry S. Acta Anaesthesiol Scand 2008; 52(6). Characteristics and long-term outcome of acute exacerbations in chronic obstructive pulmonary disease: an analysis of cases in the Swedish Intensive Care Registry, Vol. 2002. 2006. pp. 759-65.

22. Wildman MJ, Sanderson C, Groves J, Reeves BC, Ayres J, Harrison D, Young D, Rowan K. Predicting mortality for patients with exacerbations of COPD and Asthma in the COPD and Asthma Outcome Study (CAOS). QJM. 2009;102(6):389-99.

23. Funk GC, Bauer P, Burghuber OC, Fazekas A, Hartl S, Hochrieser H, Schmutz R, Metnitz P. Prevalence and prognosis of COPD in critically ill patients between 1998 and 2008. Eur Respir J. 2013;41(4:792-9.

24. Chandra D, Stamm JA, Taylor B, Ramos RM, Satterwhite L, Krishnan JA, et al. Outcomes of noninvasive ventilation for acute exacerbations of chronic obstructive pulmonary disease in the United States, 1998-2008. Am J Respir Crit Care Med 2012;185(2):152-9.

25. Chung LP, Winship P, Phung S, Lake F, Waterer G. Fiveyear outcome in COPD patients after their first episode of acute exacerbation treated with non-invasive ventilation. Respirology. 2010;15(7):1084-91.

26. Echave-Sustaeta J, Casanova LC, Lujaìn RG, Catalan JS, de la Caìmara AG, and Encuentra AL. Prognosis following acute exacerbation of COPD treated with non-invasive mechanical ventilation. Archivos de Bronconeumologiìa (English Edition) 2010;46(8):405-10.

27. Schols AM, Slangen JOS, Volovics L, Wouters EF. Weight loss is a reversible factor in the prognosis of chronic obstructive pulmonary disease. Am J Respir Crit Care Med. 1998;157(6):1791-7.

28. Köhnlein T, Windisch W, Köhler D, Drabik A, Geiseler J, Hartl S, Karg O, Laier-Groeneveld G, Nava S, Schönhofer B, Schucher B, Wegscheider K, Crieìe CP, Welte T. Noninvasive positive pressure ventilation for the treatment of severe stable chronic obstructive pulmonary disease: a prospective, multicentre, randomised, controlled clinical trial. LancetRespir Med. 2014;2(9):698-705.

29. Struik FM, et al. Nocturnal non-invasive ventilation in COPD patients with prolonged hypercapnia after ventilatory support for acute respiratory failure: a randomised, controlled, parallel-group study. Thorax. 2014;69.9:826-34.

30. Galli JA, et al. Home non-invasive ventilation use following acute hypercapnic respiratory failure in COPD. Respir Med. 2014;108.5:722-8. 